\title{
DOENÇAS E CARACTERÍSTICAS FÍSICAS E QUÍMICAS PÓS-COLHEITA EM MARACUJÁ AMARELO DE CULTIVO CONVENCIONAL E ORGÂNICO NO CENTRO OESTE PAULISTA ${ }^{1}$
}

\author{
IVAN HERMAN FISCHER ${ }^{2}$,MARIA CECÍLIA DE ARRUDA ${ }^{3}$, APARECIDA MARQUES DE ALMEIDA ${ }^{4}$, \\ MARIA JOSÉ DE MARCHI GARCIA ${ }^{5}$, ELISANGELA MARQUES JERONIMO ${ }^{6}$, RAQUEL NAKAZATO PINOTTI ${ }^{7}$, \\ ROSEMARY MARQUES DE ALMEIDA BERTANI ${ }^{8}$
}

RESUMO-Após a colheita do maracujá-amarelo, ocorre aumento na suscetibilidade do fruto às podridões e significativa perda de massa fresca. Diante disso, objetivou-se identificar e quantificar as doenças pós-colheita e avaliar as características físicas e químicas de frutos de maracujazeiro-amarelo produzidos em sistemas de cultivo convencional e orgânico. Os frutos foram individualizados e submetidos a $24 \mathrm{~h}$ de câmara úmida, permanecendo por mais 13 dias a $25 \pm 2^{\circ} \mathrm{C}$ e $70-80 \%$ de UR. As doenças e o índice de murchamento foram avaliados visualmente após a coleta do fruto e a cada três dias. Os frutos também foram caracterizados quanto à espessura da casca, rendimento em polpa e teores de acidez titulável e de sólidos solúveis. A ocorrência de podridões foi elevada, tanto no pomar orgânico como no convencional. A antracnose foi a principal doença, com $100 \%$ de incidência nos frutos de ambos os pomares, seguida pela podridão de Fusarium, com $25,5 \%$ no convencional e $19,0 \%$ no orgânico. Já para a podridão de Phomopsis, a incidência foi superior no pomar convencional $(11,0 \%)$, comparado ao orgânico $(2,0 \%)$. Com auxílio de uma escala diagramática, estimou-se a severidade da antracnose, de 34,1\% nos frutos orgânicos e de 39,8\% nos frutos do pomar convencional. Os frutos orgânicos apresentaram-se maiores, com maior espessura da casca, menor rendimento em polpa e maior teor de sólidos solúveis. O índice de murchamento não diferiu entre os maracujás dos dois sistemas de cultivo. Com base nos resultados obtidos, medidas de controle fitossanitárias no campo e na pós-colheita devem ser adotadas, visando a obter frutos de maior qualidade.

Termos para indexação: Passiflora edulis, doenças, qualidade.

\section{POSTHARVEST DISEASES AND PHYSICAL CHEMICAL CHARACTERISTICS OF YELLOW PASSION FRUIT FROM ORGANIC AND CONVENTIONAL CROPS IN THE MIDWEST REGION OF SÃO PAULO STATE}

\begin{abstract}
After harvested, yellow passion fruit have an increase in rot susceptibility and significant loss of fresh mass. The purposes of this work were to identify and quantify post harvest diseases and to evaluate the physical chemical characteristics of yellow passion fruits grown under conventional and organic cropping systems. Fruits from both cropping systems were individualized and kept in a humid chamber for $24 \mathrm{~h}$, previously at 13 days period at $25 \pm 2^{\circ} \mathrm{C}$ and $70-80 \% \mathrm{RH}$. The incidence of diseases and the shrinkage index were visually assessed after fruit gathering and, then, every three days. Fruits were also characterized as to skin thickness, pulp content, titratable acidity and soluble solids content. There was high incidence of post harvest diseases in both conventional and organic cropping systems. Anthracnose was the main disease, with $100 \%$ of incidence on fruits from both cropping systems, followed by Fusarium rot, with $25.5 \%$ in the conventional and $19.0 \%$ in the organic systems. Incidence of Phomopsis rot was higher in the conventional crop (11.0\%) than in the organic crop $(2.0 \%)$. Anthracnose severity was estimated using a diagrammatic scale, and corresponded to $34.1 \%$ in organic fruits and $39.8 \%$ in conventional ones. Organic fruits were bigger, and presented greater skin thickness, less pulp content and greater soluble solids amount. Shrinkage indexes of fruit from both cropping systems did not differ. The results suggest the adoption of phyto sanitary control in the field and during post harvest stage aiming fruits with better quality.
\end{abstract}

Index Terms: Passiflora edulis, diseases, quality.

\section{INTRODUÇ̃̃O}

A demanda crescente por alimentos saudáveis, produzidos sem agressões ao meio ambiente, valorizando a diversidade biológica e sem o uso de adubos químicos e agrotóxicos, é uma tendência que favorece a criação de novas oportunidades, principalmente aos pequenos produtores rurais. O sistema de cultivo orgânico do maracujazeiro-amarelo

(Trabalho 148-06). Recebido em : 27-09-2006. Aceito para publicação em: 08-05-2007.

2 Ms. Pesquisador científico da APTA Regional Bauru, Av. Rodrigues Alves, 40-40, 17030-000, Bauru-SP, E-mail: ihfische@aptaregional.sp.gov.br

${ }^{3}$ Dra. Pesquisadora científica da APTA Regional Bauru, E-mail: mcarruda@aptaregional.sp.gov.br.

${ }^{4}$ Dra. Pesquisadora científica da APTA Regional Bauru, E-mail almeida@aptaregional.sp.gov.br.

${ }^{5}$ Dra. Pesquisadora científica da APTA Regional Bauru, E-mail; mjdemarchi@aptaregional.sp.gov.br.

${ }^{6}$ Dra. Pesquisadora científica da APTA Regional Jaú, Rod. SP 304, Jaú/Bariri, 17201-970, Jaú-SP, E-mail: elijeronimo@aptaregional.sp.gov.br.

${ }^{7}$ Ms. Pesquisadora científica da APTA Regional Bauru, E-mail: raquelnakazato@aptaregional.sp.gov.br

${ }^{8}$ Dra. Pesquisadora científica da APTA Regional Marília, R. Andrade Neves, 81, 17515-400, Marília-SP, E-mail: rosemary.bertani@aptaregional.sp.gov.br. 
(Passiflora edulis Sims f. flavicarpa Deg.) vem sendo adotado por produtores de vários Estados, como São Paulo, Paraná e Rio de Janeiro; entretanto, há deficiência de informações científicas sobre o cultivo orgânico da cultura, pois elas enfocam, em sua maioria, informações sobre o cultivo orgânico em geral, de hortaliças e café (Silva et al., 2005; Toda Fruta, 2005).

Os danos, a redução na quantidade ou na qualidade de um produto, na pós-colheita, podem ser de natureza física, fisiológica e patológica e expressam-se desde a colheita até o consumidor (Snowdon, 1990; Kluge et al., 2001). Após a colheita, a suscetibilidade do maracujá às podridões é elevada, com ocorrência significativa de perda de massa fresca e fermentação da polpa. Sob condições normais de temperatura ambiente, pode ser conservado por sete a dez dias (Arjona et al., 1992). O reduzido tempo de vida útil após a colheita, associado ao curto período de colheita, condiciona a oferta e os preços no mercado. Sabe-se que, para uma boa aceitação pelos consumidores, os frutos devem estar túrgidos, com a casca amarela, lisa ou pouco enrugada, e com ausência de manchas e de defeitos que possam afetar a qualidade da polpa, tais como rachaduras, presença de fungos e sinais de ataque por insetos (Cetec, 1985).

Dentre as várias doenças identificadas em pós-colheita do maracujá-amarelo, a mais importante é a antracnose, causada por Colletotrichum gloeosporioides Pens, que causa manchas escuras na casca, depreciando a aparência do fruto. Na maioria das vezes, o fruto já vem infectado do campo, portanto deve-se adotar um manejo preventivo adequado, até próximo à florada e, também, durante o desenvolvimento dos frutos (Yamashiro, 1980). Outros microrganismos também podem causar podridões póscolheita em maracujá, entre os quais, Alternaria alternata $(\mathrm{Fr} .: \mathrm{Fr})$ Keissl e A. passiflorae Simm., Septoria passiflorae Louw, Aspergillus niger van Tieghem, Cladosporium sp. Fusarium spp., Penicillium expansum Link, Phytophthora nicotianae var. parasitica (Dastur) Waterh, Rhizopus stolonifer (Ehreub ex Fr.) Lind, Pseudomonas syringae pv. passiflorae (Reid) Burkh, Xanthomonas campestris pv. passiflorae Per. (Kretzschmar, 1991; Lombardi, 2001), Phomopsis spp., Lasiodiplodia theobromae Pat., Pestalotiopsis spp., Botrytis cinereae Pers., Sclerotinia sclerotiorum (Lib.) de Bary (Kagiwata, 1990) e Trichoderma harzianum Rifai (Ismail, 2000).

A caracterização de danos pós-colheita visa a facilitar a tomada de decisão por parte do produtor, do atacadista e do varejista quanto à necessidade de investimento em medidas de prevenção, pois só é possível avaliar se a adoção de uma medida de controle será lucrativa ou não, após quantificar os danos causados por determinado patógeno (Baritelle \& Gardner, 1984). Diante disso, objetivou-se identificar e quantificar as doenças pós-colheita e avaliar as características físicas e químicas de frutos de maracujazeiro-amarelo produzidos em dois sistemas de cultivo, o convencional e o orgânico.

\section{MATERIAL E MÉTODOS}

Foram utilizados frutos provenientes de pomar com cultivo orgânico, localizado em Paulistânia-SP (coordenadas $22^{\circ} 34^{\prime} 42^{\prime \prime} \mathrm{S}$ e $49^{\circ} 24^{\prime} 10^{\prime \prime} \mathrm{W}$, com $645 \mathrm{~m}$ de altitude) e de cultivo convencional, localizado em Bauru-SP (coordenadas 22 $19^{\prime} 18^{\prime \prime}$ S e 4904'13" W, com 526 m de altitude). O clima da região de Bauru é subtropical, sendo que a temperatura média diária, no período de dezembro de 2005 a fevereiro de 2006 , foi de $25,8^{\circ} \mathrm{C}$, a média diária mínima de $21,8^{\circ} \mathrm{C}$ e a média diária máxima de $29,1^{\circ} \mathrm{C}$. A precipitação média mensal, no referido período, foi de 210,2 $\mathrm{mm}$. Os dois pomares estudados apresentavam algumas características semelhantes, tais como: produtividade estimada entre 30-32 t.ha-1, cerca de 1.200 plantas da seleção Afruvec, conduzidas em espaldeira (um fio de arame a 1,80 $\mathrm{m}$ do solo), com dois anos de idade, espaçamento $(2,5 \times 2,5 \mathrm{~m})$ e ausência de irrigação, além da não-ocorrência do vírus do endurecimento dos frutos e da mancha bacteriana, importantes doenças na região Centro-Oeste Paulista. No pomar convencional, o controle fitossanitário caracterizou-se por aplicações foliares quinzenais e alternadas dos fungicidas mancozeb + oxicloreto de cobre $(0,15 \%)$ e tiofanato metílico $(0,05 \%)$, e esporadicamente do inseticida fenthion $(0,05 \%)$. No manejo orgânico, foram realizadas aplicações foliares mensais de biofertilizante a 2,0\% e urina de vaca a $2,0 \%$, além da aplicação anual de calda bordalesa, contendo $1 \%$ de sulfato de cobre e $1 \%$ de cal virgem. O biofertilizante foi preparado pela mistura de $1 \mathrm{~kg}$ do componente para fermentação e compostagem Microgeo ${ }^{\circledR}$ (substâncias recalcitrantes, preparados biodinâmicos, pentoses, minerais e farelos), $4 \mathrm{~L}$ de esterco de boi curtido e $20 \mathrm{~L}$ de água, agitando-se diariamente e utilizando o biofertilizante 15 dias após a mistura inicial dos insumos em um tanque.

As principais características químicas de solo, do segundo ano de produção, nos pomares convencional e orgânico, foram respectivamente: $\mathrm{pH}\left(\mathrm{em} \mathrm{CaCl}_{2}\right)$ : 4,6 e 6,2; matéria orgânica: 17 e 11 g.dm $\mathrm{dm}^{-3} ;:$ P: 2 e 8 mg.dm ${ }^{-3}$; S: 0 e 3 mg.dm ${ }^{-3}$; em mmol $\cdot \mathrm{dm}^{-3}: \mathrm{K}: 3,1$ e 3,5; Ca: 12 e 17; Mg: 5 e 11; H Al: 26 e 11; CTC: 46 e 42, e em \%: V: 42 e 74. Considerando-se essas características e a exigência nutricional do maracujazeiro, procederam-se as adubações, segundo os critérios recomendados em Piza Júnior et al. (1997). As fontes utilizadas no pomar convencional foram uréia (140 kg.ha ${ }^{-1}$ de N), superfosfato simples $\left(120 \mathrm{~kg} \cdot\right.$ ha $\left.^{-1} \mathrm{de}_{2} \mathrm{O}_{5}\right)$ e cloreto de potássio $\left(120 \mathrm{~kg} \cdot \mathrm{ha}^{-1}\right.$ de $\left.\mathrm{K}_{2} \mathrm{O}\right)$. Em relação à adubação orgânica, foram utilizados 5 t.ha $\mathrm{h}^{-1}$. nno $^{-1}$ de esterco de boi curtido no cultivo convencional e 9 t.ha- ${ }^{-1}$.ano ${ }^{-1}$ no orgânico.

Frutos com coloração da casca $50 \%$ amarela foram colhidos aleatoriamente, tomando-se o cuidado de amostrar plantas homogêneas na área. Foram realizadas duas colheitas de 100 frutos, em cada sistema de cultivo, em janeiro e fevereiro de 2006. Os frutos foram acondicionados em caixas plásticas forradas com saco 'tipo bolha' e transportados cuidadosamente até o laboratório da APTA Regional - Bauru-SP, onde estes foram individualizados em bandejas plásticas e armazenados durante 14 dias a $25 \pm 2^{\circ} \mathrm{C}$ e $70-80 \%$ de UR. Nas primeiras 24 horas de armazenamento, os frutos foram submetidos à câmara úmida, visando a favorecer a ocorrência das doenças pós-colheita. A incidência (\%) de doenças e a severidade da antracnose foram avaliadas visualmente, aos $0 ; 4 ; 7 ; 11$ e 14 dias da colheita dos frutos.

Quando havia dúvidas sobre a doença em questão, foram preparadas lâminas com estruturas do patógeno para sua 
identificação sob microscópio óptico e realizado o isolamento do mesmo em meio de cultura batata-dextrose-ágar (BDA). Os patógenos encontrados tiveram a patogenicidade confirmada através da inoculação em frutos sadios, substituindo-se discos da casca por discos de micélio (5,0 mm de diâmetro). Os discos de micélio foram provenientes de colônias monospóricas cultivadas em meio BDA, durante sete dias (Moraes et al., 2006).

$\mathrm{O}$ índice de murchamento foi determinado por meio de uma escala de notas desenvolvida por Mota (1999), em que se relacionam a perda de volume e o grau de murcha dos frutos. Assim: $0=0 \%$ de perda de volume; $1=3 \%$ de perda de volume; $2=6 \%$ de perda de volume; $3=9 \%$ de perda de volume; $4=12 \%$ de perda de volume, e $5=15 \%$ de perda de volume.

No dia da colheita, seis repetições de três frutos foram utilizadas para a caracterização dos seguintes parâmetros: a) massa fresca do fruto; b) diâmetro; c) comprimento; d) espessura da casca; e) rendimento em polpa; f) teor de sólidos solúveis (SS); g) teor de acidez titulável (AT); h) "ratio" (SS/AT). Os teores de sólidos solúveis e de acidez titulável foram determinados de acordo com o método descrito pela AOAC (1997).

A incidência média dos diferentes patógenos foi submetida à análise de variância e comparada por meio de teste não-paramétrico de comparação de múltiplas proporções, ao nível de $5 \%$ de probabilidade, conforme Zar (1999).

Os resultados referentes à caracterização física e química foram submetidos à análise de variância, e as médias, comparadas pelo teste de Tukey (5\%). Os resultados do índice de murchamento foram submetidos à análise do desvio-padrão, onde a diferença entre dois tratamentos maior que a soma de dois desvios-padrão foi considerada significativa $(p<0,05)$ (Moretti et al., 2002).

\section{RESULTADOS E DISCUSSÃO}

\section{Incidência de doenças e severidade da antracnose}

A ocorrência de doenças pós-colheita nos frutos de maracujazeiro-amarelo foi elevada, tanto no pomar orgânico como no convencional (Tabela 1). Os resultados obtidos confirmam a importância econômica das doenças pós-colheita em maracujáamarelo, pois a maioria delas desqualifica o fruto para comercialização, como destacado por Lutchmeah (1992) e Junqueira et al. (2003), que mencionam perdas de até $40 \%$ da produção durante a comercialização.

O principal patógeno encontrado nos frutos foi $C$. gloeosporioides, com $100 \%$ de incidência nos dois pomares, significativamente superior à incidência dos demais patógenos (Tabela 1). Maior ocorrência de C. gloeosporioides (95\%) também foi observada por Benato et al. (2001), em frutos procedentes de Vera Cruz-SP.

Estimou-se a severidade média de antracnose de 34,1\% nos frutos orgânicos e de 39,8\% nos frutos do pomar convencional, aos 14 dias de armazenamento (Figura 1). Esta elevada ocorrência de antracnose deve-se, provavelmente, ao elevado inóculo do patógeno em pomares com mais de um ano de produção, como é o caso deste estudo, cujas plantas apresentavam muitos ramos secos que servem de fonte de inóculo para a doença (Liberato \& Costa, 2001).

A podridão de Fusarium, causada por $F$. proliferatum (Matsushima) Nirenberg, apresentou incidência média de 9,0\% e $25,5 \%$ nos frutos oriundos do pomar convencional e de $6,0 \%$ e $19,0 \%$ nos frutos de pomar orgânico, após sete e quatorze dias, respectivamente (Tabela 1 ).

A podridão peduncular, causada por Phomopsis tersa (Sacc.) B. Sutton, atingiu incidência média de $11,0 \%$ em maracujá do pomar convencional, diferindo significativamente $(p<0,05)$ do pomar orgânico, com apenas $2,0 \%$ de incidência média (Tabela 1). Em Mauritius, a podridão peduncular de Phomopsis foi considerada uma importante doença pós-colheita, afetando $40 \%$ dos frutos de maracujazeiro-amarelo (Lutchmeah, 1992).

Com exceção da antracnose, que expressou sintomas na colheita, as demais doenças apresentaram maior desenvolvimento a partir da primeira semana de armazenamento dos frutos (Tabela 1). Freqüências baixas, sem diferenças significativas entre si, foram observadas para os patógenos $L$. theobromae, $(1,0 \%)$, A. alternata $(0,5 \%)$, P. expansum $(0,5 \%) \mathrm{e}$ Trichoderma sp. (0,5\%), porém contribuíram para aumentar as perdas pós-colheita de maracujá. Os resultados corroboram os encontrados por Lutchmeah (1993) em frutos procedentes de mercados varejistas e packinghouse, em que foram observados nove tipos de doenças, sendo as mais comuns a antracnose, a podridão de Fusarium e a podridão de Phomopsis.

Os índices de perdas de frutos pós-colheita são geralmente reflexos dos percentuais de incidência das doenças nessa fase, uma vez que os frutos são desqualificados para a comercialização pela simples presença dos sintomas (Gullino, 1994). A grande incidência e diversidade de doenças constatada neste estudo sugerem a necessidade do emprego de medidas de controle mais efetivas durante as fases de produção e pós-colheita de maracujá, visando a propiciar a redução dessas perdas.

Os métodos químicos atuam sobre patógenos de ferimentos e de infecção quiescente, no entanto deve-se ter algumas precauções quanto à fitotoxicidade, resíduos, espectro de ação e resistência (Benato et al., 2001). A crescente restrição ao uso de fungicidas, por questões de segurança alimentar e impacto ambiental, tem estimulado o uso de métodos alternativos e biológicos para controle de doenças pós-colheita (Stevens et al.,1991).

\section{Características físicas e químicas}

Após a colheita, o fruto de maracujazeiro inicia um rápido processo de desidratação. Em conseqüência, ocorre enrugamento da casca e perda de massa e de volume, depreciando sua aparência externa e reduzindo o período de comercialização (Castro, 1994).

O índice de murchamento não diferiu entre os maracujás dos dois sistemas de cultivo $(p<0,05)$, atingindo valor de 3,4 aos 14 dias após a colheita (Figura 2), superior ao encontrado por Mota (1999), que estimou índice de murchamento de 1,7 em maracujás, após 14 dias de armazenamento a $22 \pm 2^{\circ} \mathrm{C}$.

O controle do murchamento é de fundamental importância, visto que o maracujá, geralmente, é comercializado por quilo e pelo fato de o consumidor comprar os frutos pela aparência. A desidratação do fruto, que leva ao murchamento, ocorre pelo 


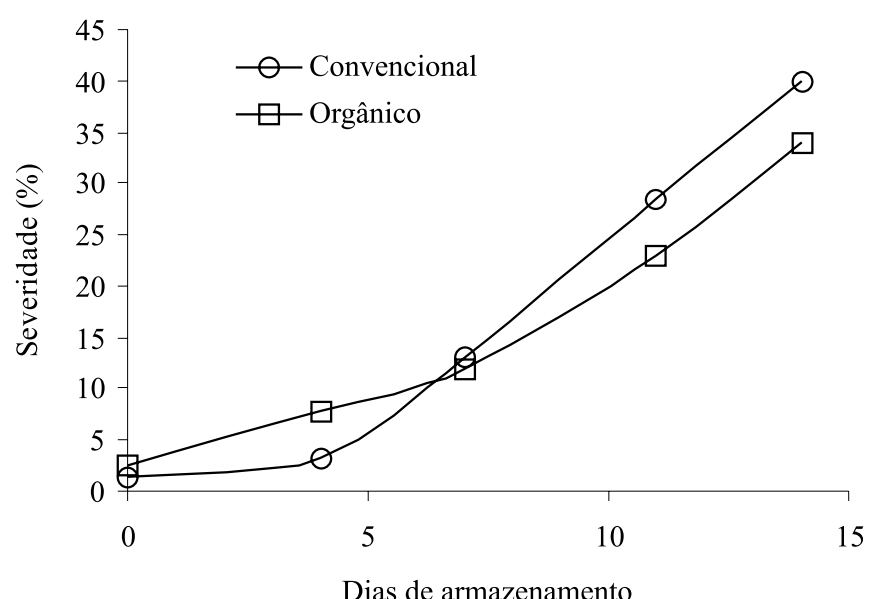

FIGURA 1 - Severidade de antracnose em frutos de maracujazeiroamarelo provenientes de sistemas de cultivo convencional e orgânico, durante 14 dias de armazenamento a $25 \pm 2^{\circ} \mathrm{C}$ e $70-80 \%$ de UR.

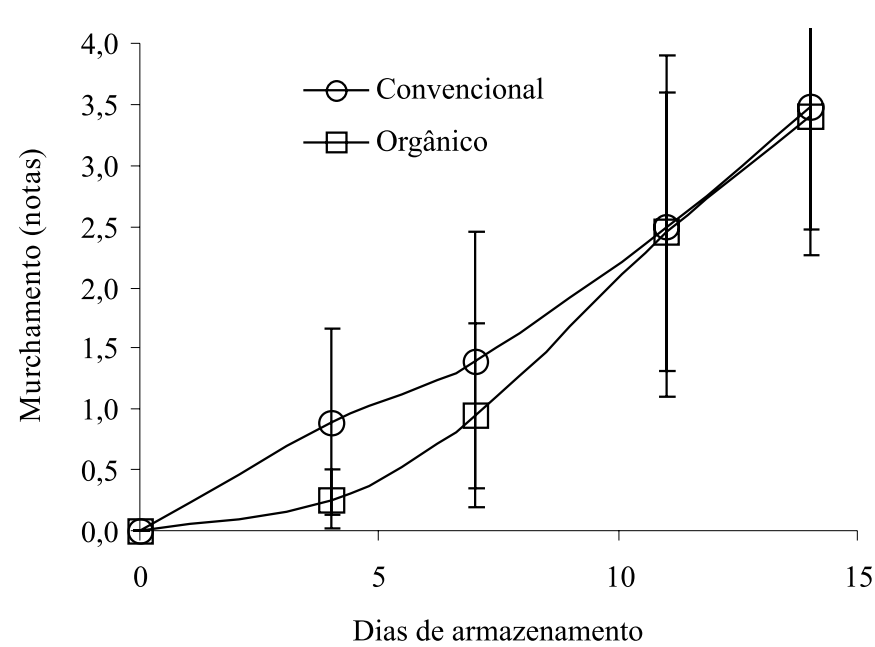

FIGURA 2 - Índice de murchamento de frutos de maracujazeiroamarelo convencional e orgânico, durante 14 dias de armazenamento a $25 \pm 2^{\circ} \mathrm{C}$ e $70-80 \%$ de UR.

TABELA 1 - Incidência (\%)* de patógenos pós-colheita em maracujá-amarelo produzido em sistema convencional (Bauru-SP) e orgânico (Paulistânia-SP), após sete e quatorze dias de armazenamento, em 2006

\begin{tabular}{llllll}
\hline \multirow{2}{*}{ Patógeno } & \multicolumn{2}{c}{ Convencional } & & \multicolumn{2}{c}{ Orgânico } \\
\cline { 2 - 3 } \cline { 5 - 6 } & $7^{\circ} \mathrm{dia}$ & $14^{\circ} \mathrm{dia}$ & & $7^{\circ} \mathrm{dia}$ & $14^{\circ} \mathrm{dia}$ \\
\hline Colletotrichum gloeosporioides & $98,5 \mathrm{aA} * *$ & $100,0 \mathrm{aA}$ & & $100,0 \mathrm{aA}$ & $100,0 \mathrm{aA}$ \\
Fusarium proliferatum & $9,0 \mathrm{bB}$ & $25,5 \mathrm{aB}$ & & $6,0 \mathrm{bB}$ & $19,0 \mathrm{aB}$ \\
Phomopsis tersa & $3,5 \mathrm{bC}$ & $11,0 \mathrm{aC}$ & & $1,0 \mathrm{bC}$ & $2,0 \mathrm{bC}$ \\
Lasiodiplodia theobromae & $0,0 \mathrm{aD}$ & $0,0 \mathrm{aD}$ & & $0,0 \mathrm{aC}$ & $1,0 \mathrm{aC}$ \\
Alternaria alternata & $0,0 \mathrm{aD}$ & $0,5 \mathrm{aD}$ & & $0,0 \mathrm{aC}$ & $0,0 \mathrm{aC}$ \\
Penicillium expansum & $0,0 \mathrm{aD}$ & $0,5 \mathrm{aD}$ & & $0,0 \mathrm{aC}$ & $0,0 \mathrm{aC}$ \\
Trichoderma sp. & $0,0 \mathrm{aD}$ & $0,5 \mathrm{aD}$ & & $0,0 \mathrm{aC}$ & $0,0 \mathrm{aC}$ \\
\hline
\end{tabular}

* Média de duas colheitas de 100 frutos cada.

** Dados seguidos pela mesma letra minúscula na linha e maiúscula na coluna não diferem entre si, ao nível de $5 \%$, pelo teste não- paramétrico de comparação de múltiplas proporções.

TABELA 2 - Características físicas e químicas de frutos de maracujazeiro-amarelo produzidos em sistema de cultivo convencional (Bauru- SP) e orgânico (Paulistânia- SP), em 2006

\begin{tabular}{|c|c|c|c|c|c|c|c|c|}
\hline \multirow{2}{*}{$\begin{array}{l}\text { Sistema de } \\
\text { cultivo }\end{array}$} & \multicolumn{8}{|c|}{ Variáveis } \\
\hline & $\begin{array}{l}\text { Massa } \\
(\mathrm{g})\end{array}$ & $\begin{array}{l}\text { Diâmetro } \\
(\mathrm{mm})\end{array}$ & $\begin{array}{l}\text { Comprimento } \\
\text { (mm) }\end{array}$ & $\begin{array}{c}\text { Espes. } \\
\text { casca } \\
(\mathrm{cm})\end{array}$ & $\begin{array}{c}\text { Rend. } \\
\text { polpa } \\
(\%)\end{array}$ & $\begin{array}{c}\mathrm{SS}^{1} \\
\left({ }^{\circ} \text { Brix }\right)\end{array}$ & $\begin{array}{c}\mathrm{AT}^{2} \\
(\% \text { ac. } \\
\text { cítrico) }\end{array}$ & $\begin{array}{l}\text { "Ratio" } \\
\text { (SS/AT) }\end{array}$ \\
\hline Convencional & $156,13 a^{*}$ & $63,70 \mathrm{~b}$ & $85,90 \mathrm{~b}$ & $0,36 \mathrm{~b}$ & $46,40 \mathrm{~b}$ & $12,35 \mathrm{~b}$ & $4,39 \mathrm{a}$ & $2,81 \mathrm{a}$ \\
\hline Orgânico & $175,27 \mathrm{a}$ & $76,30 \mathrm{a}$ & $91,80 \mathrm{a}$ & $0,86 \mathrm{a}$ & $33,94 \mathrm{a}$ & $15,58 \mathrm{a}$ & $5,15 \mathrm{a}$ & $3,03 \mathrm{a}$ \\
\hline CV (\%) & 10,59 & 3,70 & 2,97 & 8,99 & 16,36 & 8,70 & 4,51 & 17,44 \\
\hline
\end{tabular}

${ }^{1} \mathrm{SS}=$ sólidos solúveis; ${ }^{2} \mathrm{AT}=$ acidez titulável*Dados seguidos pela mesma letra minúscula na coluna não diferem entre si, ao nível de $5 \%$, pelo teste de Tukey. 
processo de transpiração, o qual é influenciado por vários fatores, tais como: espessura da casca, presença e número de estômatos, temperatura, umidade relativa do ambiente de armazenamento e presença de barreiras artificiais (Chitarra \& Chitarra, 2005). Neste trabalho, a espessura da casca do maracujá orgânico apresentouse maior, mas isto não resultou em menor índice de murchamento.

Os frutos do sistema orgânico apresentaram maior tamanho e, de acordo com o sistema de classificação do Programa Brasileiro para Modernização da Horticultura (Hortibrasil, 2004), enquadram-se em classe superior comparada ao convencional. No entanto, o maior tamanho não refletiu em maior massa do fruto, em virtude do menor rendimento em polpa dos mesmos (Tabela 2).

Em relação à espessura da casca, os frutos orgânicos apresentaram espessura significativamente maior que os frutos cultivados em sistema convencional. Nascimento (1996) cita que, tanto a indústria de suco concentrado como o mercado da fruta in natura consideram a espessura de casca um fator relevante para a classificação do fruto, por ser inversamente proporcional ao rendimento de polpa. Este fato pode ser comprovado neste trabalho, onde frutos com maior espessura da casca apresentaram menor rendimento em polpa e vice-versa. Embora a maior espessura da casca reflita em menor rendimento em polpa, essa característica confere ao fruto maior resistência ao transporte a longas distâncias.

Os frutos do sistema orgânico e convencional não diferiram quanto ao teor de acidez titulável e "ratio". Em relação ao teor de sólidos solúveis, valores superiores $(p<0,05)$ foram encontrados em frutos provenientes do sistema orgânico (Tabela 2). Segundo Chitarra \& Chitarra (2005), o referido parâmetro químico representa uma das melhores formas de avaliação do grau de doçura do produto. Os resultados para sólidos solúveis são discordantes dos obtidos por Amaro \& Monteiro (2001), que verificaram maior teor de sólidos solúveis em frutos provenientes de sistema convencional. De forma geral, os estudos comparativos entre características físicas e químicas de diversos produtos hortícolas, cultivados em sistema orgânico e convencional, mostraram resultados variáveis (Darolt, 2003), necessitando de mais estudos. A avaliação dos teores de macronutrientes do solo, ao final do experimento, possivelmente permitiria verificar alguma relação dos mesmos com o teor de sólidos solúveis.

\section{CONCLUSÕES}

1- A ocorrência de doenças em pós-colheita foi elevada em maracujá-amarelo, tanto para o plantio convencional como para o orgânico. A antracnose foi a principal doença, com 100\% de incidência nos frutos dos dois pomares, seguida pela podridão de Fusarium.

2- Os frutos produzidos pelo sistema orgânico apresentaram-se maiores, com espessura da casca maior, menor rendimento em polpa, maior teor de sólidos solúveis e acidez titulável e SS/AT semelhantes aos frutos produzidos pelo sistema convencional.

3- Com base nos resultados obtidos, medidas de controle fitossanitárias no campo e na pós-colheita devem ser adotadas, visando a obter frutos de maior qualidade.

\section{AGRADECIMENTOS}

Ao Prof. Dr. Ludwig H. Pfenning, do Departamento de Fitopatologia da Universidade Federal de Lavras, pela identificação dos isolados de Fusarium proliferatum encontrados em frutos de maracujazeiro.

\section{REFERÊNCIAS}

AMARO, A.P.; MONTEIRO, M. Rendimento de extração da polpa e características físico-químicas do maracujá-amarelo (Passiflora edulis f. flavicarpa Sims. Deg.) produzido por cultivo orgânico e convencional em relação à cor da casca. Alimentos \& Nutrição, Araraquara, v.12,p.171-184, 2001.

AOAC. Official methods of analysis of the Association of Official Analytical Chemists International. $3^{\text {rd }}$ ed. Washington: AOAC, 1997. v.2, p.37-45.

ARJONA, H.E.; MATTA, F.B.; GARNER, J.O. Temperature and storage time affect quality of yellow passion fruit. HortScience, Alexandria, v.27, n.7, p.809-810, 1992.

BARITELLE, J.L.; GARDNER, P.D. Economic losses in the food and fiber system: from the perspective of an economist. In: MOLINE, H.E. (Ed.) Postharvest pathology of fruits and vegetables: postharvest losses in perishable crops. Davis: University of California Agricultural Experiment Station Bulletin, 1984. p.4-10.

BENATO, E.A.; CIA, P.; SIGRIST, J.M.M.; SOUZA, N.L. de. Efeito do tratamento hidrotérmico no controle de podridões póscolheita em maracujá-amarelo. Summa Phytopathologica, Jaboticabal, v.27, p.399-403, 2001.

CASTRO, J.V. MATÉRIA-PRIMA IN: ITAL. MARACUJÁ. CAMPINAS: ITAL, 1994. 26P. (SÉRIE FRUTAS TROPICAIS, 9).

CETEC. Manual para fabricação de geléias. Belo Horizonte: Fundação Centro Tecnológico de Minas Gerais, 1985. 42 p. (Série Publicações Técnicas/SPT-015).

CHITARRA, M.I.F.; CHITARRA, A.B. Pós-colheita de frutos e hortaliças: fisiologia e manuseio. 2. ed. Lavras: UFLA, 2005. $785 \mathrm{p}$.

DAROLT, M. Comparação entre a qualidade do alimento orgânico e a do convencional. In: STRINGHETA, P.C.; MUNIZ, J.N. (Ed.). Alimentos orgânicos: produção, tecnologia e certificação. Viçosa: UFV, 2003. p.289-312.

GULLINO, M.L. Lotta 'biologica a funghi agenti di marciumi della frutta in post-raccolta. Informatore Fitopatologico, Torino, v.44, p.5-13, 1994.

HORTIBRASIL 2004. Maracujá azedo. Disponível em: <http:// www.hortibrasil.org.br/ classificacao/maracuja/ maracuja.html>. Acesso em: 27 dez. 2006.

ISMAIL, M.A. Pathogenic ability and pectolytic enzymes of fungi most commonly associated with passion fruits with special reference to the effectiveness of sodium hypochlorite on the rot development. African Journal of Mycology and 
Biotechnology, Assiut, v.8, n.3, p.13-24, 2000.

JUNQUEIRA, N.T.V.; SHARMA, R.D.; JUNQUEIRA, K.P.; ANDRADE, L.R.M. Doenças constatadas na fase de póscolheita. In: SANTOS FILHO, H.P.: JUNQUEIRA, N.T. Maracujá fitossanidade. Brasília: Embrapa Informações Tecnonológica, 2003. p.32-36.

KAGIWATA, T. Fruit rot of passion fruit caused by Botrytis cinerea and Sclerotinia sclerotiorum. Japanese Journal of Tropical Agricuture, Tokyo, v.34, n.1, p.35-39, 1990.

KLUGE, R.; SCARPARE FILHO, J.A.; JACOMINO, A.O.; PEIXOTO, C.P. Distúrbios fisiológicos em frutos. Piracicaba: FEALQ, 2001.

KRETZSCHMAR, A.A. Controle biológico de patógenos que ocorrem em pós-colheita. In: BETTIOL, W (Ed.). Controle biológico de doenças de plantas. Jaguariúna: Centro Nacional de Pesquisa Meio Ambiente/Embrapa, 1991. p.53-69.

LIBERATO, J. R.; COSTA, H. Doenças fúngicas, bacterianas e fitonematóides. In: BRUCKNER, C.H.; PICANÇO, M. (Ed.). Maracujá. tecnologia de produção, pós-colheita, agroindústria, mercado. Porto Alegre: Cinco Continentes, 2001.p.243-276.

LOMBARDI, R. Classificação do maracujá permite a conquista de novos mercados. Frutas e Legumes, São Paulo, v.2, n.10, p.24-27, 2001.

LUTCHMEAH, R.S. A new disease of passion fruit in Mauritius: postharvest steam-end rot caused by Phomopsis tersa. Plant Pathology, Oxford, v.41, p.772-773, 1992.

LUTCHMEAH, R.S. Common field and post-harvest diseases of passion fruit (Passiflora edulis f. Flavicarpa) and the associated fungi in Mauritis. Revue Agricole et Sucriere de L'lle Maurice, Île Maurice, v.72, n.1-2, p.55-59, 1993.

MORAES, W.S.; ZAMBOLIM, L.; LIMA, J.D. Incidência de fungos em pós-colheita de banana 'Prata-anã' (Musa AAB). Summa Phytopathologica, Botucatu, v.32 n.1, p.67-70, 2006.

MORETTI, C.L.; MAROUELLI, W.A.; SILVA, W.L.C. Respiratory activity and browing of minimally processed sweet potatoes. Horticultura Brasileira, Brasília. v.20, p.497-500, 2002.

MOTA, W.F. Conservação pós-colheita do maracujá-amarelo (Passiflora edulis Sims f. flaricarpa Deg.) influenciada por ceras e filme plástico. 1999. 58f. Dissertação (Mestrado em Fitotecnia) - Universidade Federal de Viçosa, Viçosa, 1999.

NASCIMENTO, T.B. do. Qualidade do maracujá-amarelo produzido em diferentes épocas no sul de Minas Gerais. 1996. 56f. Dissertação (Mestrado em Fitotecnia) Universidade Federal de Lavras, Lavras, 1996.

PIZA JUNIOR, C.T. (Coord.). Maracujá. In: RAIJ, B. Van; CANTARELLA, H.; QUAGGIO, J.A.; FURLANI,A.M.C.(Ed.). Recomendações de adubação e calagem para o Estado de São Paulo. 2.ed. rev. e atual. Campinas: Instituto Agronômico/Fundação IAC, 1997. 285p. (Boletim Técnico, 100).

SILVA, T.T.; DELLA MODESTA, R.C.; PENHA, E.M.; MATTA, V.M.; CABRAL, L.M.C. Suco de maracujá orgânico processado por microfiltração. Pesquisa Agropecuária Brasileira, Brasília, v.40, n.4, p.419-422, 2005.

SNOWDON,A.L. Postharvest, a color atlas of diseases $\&$ disorders of fruits \& vegetables. Boca Raton: CRC
Press, 1990. 302p.

STEVENS, C.; LU, J.Y.; KHAN, V.A.; WILSON, C.L.; CHALUTZ, E.; DROBY, S. Ultraviolet light induced resistance against postharvest diseases in vegetables and fruits. In: WILSON, C.; CHALUTZ, E. (Ed.). Biological control of postharvest diseases of fruits and vegetables. Washington: U.S. Department of Agriculture, 1991.p.268-290.

TODA FRUTA, 2005. Agricultura orgânica com enfoque para a possibilidade do cultivo orgânico do maracujazeiro. Disponível em: <http://www.todafruta.com.br/todafruta/ mostra_conteudo.asp?conteudo $=6323>$. Acesso em: 14 jun. 2006.

YAMASHIRO, T. Doenças do maracujazeiro. In: RUGGIERO, C. (Ed.). Cultura do maracujazeiro. Jaboticabal: FCAV/UNESP, 1980.p.95-102.

ZAR, J.H. More on dichotomus variables. In: ZAR, J.H. Biostatistical analyis. New Jersey: Prentice-Hall, 1999. p.516570 .

Rev. Bras. Frutic., Jaboticabal - SP, v. 29, n. 2, p. 254-259, Agosto 2007 